\title{
O Impacto do Desemprego sobre o Bem-Estar Psicológico dos Trabalhadores da Cidade de Natal
}

\author{
João Carlos Tenório Argolo \\ Maria Arlete Duarte Araújo
}

\begin{abstract}
Resumo
Trata-se de estudo dos efeitos da situação de desemprego sobre o bem-estar psicológico, que se serve de referencial teórico eminentemente psicossocial, segundo modelo explicativo de Warr (1987). Em sua metodologia semi-experimental, para testar a relação entre o desemprego e a deterioração do bem-estar psicológico, foram comparadas as médias dos escores do Questionário de Saúde Geral, de Goldberg, versão 12 itens, entre empregados $(\mathrm{N}=184)$ e desempregados $(\mathrm{N}=458)$, exercendo-se o controle de variáveis sociodemográficas. Assim, obteve-se o resultado de que a deterioração do bemestar psicológico, na amostra de empregados, foi menor que na dos desempregados, confirmando-se a hipótese de que a situação de desemprego causa deterioração do bem-estar psicológico. Também foi investigado o papel mediador das variáveis centralidade do trabalho, apoio social percebido e características sociodemográficas sobre o sofrimento psicológico dos desempregados. Provas estatísticas forneceram resultados significativos de associação, predição e $F$ value para as variáveis participação no orçamento familiar, número de filhos, apoio social percebido, religião e freqüência à igreja. Não foram encontradas associações significativas para gênero, idade, grau de instrução, renda, centralidade do trabalho e tempo de desemprego.
\end{abstract}

Palavras-chave: desemprego; bem-estar psicológico; trabalho; saúde mental.

\begin{abstract}
The present work is a descriptive study of the effects of the unemployment situation about the mental health, conceived as the variation of the psychological well-being or the presence and intensity of light mental disturbances (not psychotic). In this sense, the scores obtained in the application of the General Health Questionnaire of Goldberg was compared to a sample of employees $(\mathrm{N}=184)$ and to a sample of unemployed $(\mathrm{N}=458)$, being exercised on the samples the control of social and demographic variables. Besides that primary analysis, it was verified inside of the unemployed sample the performance of the scores of the QSG-12, under mediation of social and demographic variables, Work centrality and Social Support. The theoretical references that subsidizes the research drawing and the analyses of the results it occupies a psychosocial perspective eminently, from the treatment of the subject of the workers' unemployment as mark of the situation of the productive restructuring and also as structural component of the effective capitalist economic system in Brazil, to the understanding of the mental health while the presence and maintenance of positive lines of the psychological well-being, that surpasses the absence of pathological symptom. The statistical procedures are based in Analysis of Variance and Analysis of Regression, accompanied of tests of internal consistency of the samples and of significance tests and correlations tests (Pearson and Qui-square).
\end{abstract}

Key words: work; unemployment; psychological well-being; mental health. 


\section{INTRODUÇÃO}

Seguindo orientação psicossocial e baseada em estudos ocupacionais espanhóis, britânicos, americanos e australianos, a presente pesquisa pretende investigar o impacto do desemprego sobre o bem-estar psicológico de trabalhadores da cidade de Natal. Considera-se desemprego a perda e/ou não obtenção de um posto de trabalho regulamentar, seguida da procura de novos postos de trabalho e combinada ou não com trabalhos precários (irregulares e não-regulamentados contratualmente na forma da lei), estando o trabalhador apto para o exercício das funções pretendidas. Neste sentido, toma-se da saúde mental sua medida central: o bem-estar psicológico produzido na interação de fatores ambientais e processos psicológicos internos.

O presente estudo explora aspectos inéditos dos efeitos do desemprego no Estado do Rio Grande do Norte. A sua viabilidade funda-se em desenho metodológico simples, que utiliza dados de domínio público, de fácil acesso e passíveis de tratamento e análise estatística, capazes de conduzir à consecução dos objetivos propostos.

\section{Trabalho, Emprego e Desemprego}

Ao trabalho humano são atribuídos diversos significados; tal diversidade se deve, em parte, ao fato de que a tarefa de atribuir significados é carregada de subjetividade; portanto o trabalho humano comporta uma gama de sentidos que vão do individual ao social, referindo-se à subsistência, ao sentido existencial, à estruturação da personalidade e identidade do indivíduo, além de ocupar lugar de centralidade na organização societal, conforme assinala Borges (1998).

A despeito da diversidade em torno do significado do trabalho, tal como se verifica nas revisões bibliográficas sobre o tema, há uma confluência das opiniões de estudiosos em considerar a função econômica do trabalho ocupacional como a mais aplicável em seus trabalhos empíricos. Brief e Nord (1990) definem trabalho como "o que se faz para ganhar a vida, ou se é pago para fazer". Embora esses autores reconheçam que a visão econômica do trabalho resulta em particularização da ampla noção de trabalho, assinalam que tal visão ainda preserva largo espectro de análises para a categoria.

A função econômica do trabalho, principalmente nas sociedades ocidentais de economia capitalista, é sinônimo de emprego, e recebe destacada atenção dos 
estudiosos, em comparação aos demais significados do trabalho. Jahoda (1987) aborda esse problema por meio da Teoria da Privação, que assinala as funções psicossociais do emprego; afirma que, além do salário, outras funções dele se derivam, sendo estas subjacentes ao seu significado psicológico, a saber: motivação positiva para o trabalho, definição de identidade e status, realização de atividade estruturada, estruturação do tempo e provimento de relações sociais.

Os conceitos utilizados entre os países mais industrializados, como os integrantes da OCDE, que instrumentalizam suas metodologias de contagem do desemprego, são amplamente seguidos em muitos países do resto do mundo, até no Brasil, implicando várias incongruências existentes nos modelos adotados pelos governos e organizações patronais, algumas se destacam como mais evidentes: (1) a concepção e determinação da população ativa - todos os indivíduos aptos ao trabalho - tendente a ser superdimensionada; (2) o conceito de busca por emprego, tendente a ser rígido quanto às formas e períodos de busca de postos de trabalho; (3) as questões formuladas e apresentadas nos questionários aplicados à população, tendentes à ambigüidade ou restrição à condição de desemprego; e (4) os períodos de referência adotados como contingência à caracterização do desemprego.

Portanto a situação de desemprego, utilizada no presente projeto de pesquisa, define-se como sendo a perda e/ou não obtenção de um posto de trabalho regulamentar, seguida da procura de novos postos de trabalho e combinada ou não com trabalhos precários (irregulares e não-regulamentados contratualmente, na forma da lei), estando o trabalhador apto para o exercício das funções pretendidas.

\section{O Desemprego no Contexto da Reestruturação Produtiva}

O trabalho é a atividade humana na qual se reflete o caráter evolutivo e inovador da espécie. Os modos de produção de bens e serviços se estabeleceram ao longo do tempo, requerendo processos organizadores e métodos de divisão do trabalho capazes de mantê-los funcionando. E é no modo de produção capitalista que se evidencia melhor a divisão entre a concepção do trabalho e a sua execução, demarcada pela detenção de meios de produção e compra da força de trabalho.

Segundo Freyssinet (1994, 8-9), a gênese do desemprego está atrelada ao salário e este ao capitalismo, pois dele decorreu a combinação de três mecanismos que gerou novas categorias de necessitados de empregos, a saber: a) a destruição de formas de produção pré-capitalista, tais como agricultura familiar, artesanato e pequeno comércio; b) redução de salário do chefe de família, obrigando os outros membros da família a ingressar no mercado de trabalho; c) ritmos e 
modalidades de acumulação de capital e a mecanização da produção, como geradores de crises cíclicas na oferta de postos de trabalho.

As proposições do referido autor dão conta da gênese do desemprego, mas também se aplicam ao seu caráter estrutural, ou seja, a articulação dos mecanismos citados é, hoje, ainda mais complexa e de caráter permanente. As constantes mudanças socioeconômicas estão imbricadas com as mudanças no mundo do trabalho.

Esse momento de mudanças, de proporção mundial, ainda que não esteja consolidado nas economias do terceiro mundo, pode ser denominado de reestruturação produtiva. Suas características principais, segundo Kon (1997, 30-31), seriam:

[...] a internacionalização das atividades econômicas; a integração da produção manufatureira com a de serviços; a produção mais horizontalizada de bens e serviços, abandonando a tendência centralizadora e facilitando a distribuição; o uso maciço da tecnologia microeletrônica; a eliminação de tarefas rotineiras pela mudança tecnológica e a demanda por força de trabalho mais qualificada; maior complexidade e volatilidade do consumo; e a mudança no papel do Estado na economia.

Porém, se aos detentores do capital tais indicadores parecem constituir uma nova fórmula de gestão racional e de sucesso no que se refere à acumulação de riquezas, aos trabalhadores, principalmente dos países pobres, sobrevêm resultados desanimadores.

\section{O Desemprego no Brasil}

Alinhadas ao cenário internacional, as políticas econômicas brasileiras, marcadas pela submissão ao Fundo Monetário Internacional - FMI, com recessão, juros altos e descompromisso com a justiça social, têm no tratamento da questão do desemprego o seu maior desconforto, porquanto, mesmo considerando-se o desemprego como vicissitude do sistema capitalista, a incongruência entre o potencial de recursos materiais e humanos do país e o seu real desempenho, somada aos flagrantes desrespeitos a direitos básicos dos trabalhadores, agrava ainda mais a situação natural.

Diversos aspectos da estrutura socioeconômica do país asseveram a tendência transnacional de redução de postos de trabalho. A maioria destes está associada às políticas públicas implementadas pelo Estado e fundadas em princípios ideológicos das elites dominantes: a) a forte concentração de renda numa minoria, o que 
determina a histórica supressão e/ou precarização dos direitos básicos de cidadania da maioria, tais como: a ocupação e exploração da terra, educação pública, gratuita e de qualidade e atenção à saúde básica; b) o conseqüente déficit de qualificação das pessoas enquanto profissionais (saber fazer algo) e também enquanto cidadãos, afetados no exercício de seus princípios, senso crítico, ética e poder; c) a profunda precariedade das relações de trabalho no país, disfarçada na informalidade.

\section{O Desemprego na Cidade de Natal}

O primeiro estudo sobre a situação do mercado de trabalho na Grande Natal, realizada pelo DIEESE (2000) e Fundação SEADE, em parceria com o Governo do Estado do Rio Grande do Norte - RN, por meio do Sistema Nacional do Emprego - SINE, concluiu que, em novembro de 1999, considerando as pessoas com idade igual ou superior a 10 anos, residentes na região metropolitana (População em Idade Ativa), apenas 51,5\% atuavam no mercado de trabalho (taxa de participação), ou seja, cinco em cada dez pessoas aptas ao trabalho estavam ocupadas ou desempregadas, enquanto as outras cinco eram inativas.

Segundo o DIEESE (2000), do conjunto de pessoas que atuavam no mercado, $82,7 \%$ destes encontravam-se ocupados e 17,3\% desempregados. O estudo do DIEESE/RN também apurou que mais da metade dos desempregados (9,1\%) se encontravam na situação de desemprego aberto, enquanto os demais se dividiam em duas situações: desemprego oculto pelo trabalho precário e o desemprego oculto pelo desalento. Essa taxa é considerada elevada para o mercado de trabalho de uma cidade de porte médio. Além disso, a porcentagem é muito preocupante pelas características que esse mercado apresenta: a) a despeito da forte vocação para a atividade turística, o setor de serviços e infra-estrutura ainda exibe fraca consistência em termos de qualificação de mão-de-obra e de modernização; b) o setor industrial não tem recebido a atenção devida em termos de fomento e incentivo estatal, tal como nos Estados vizinhos e c) o apoio institucional ao desempregado concentra-se na mediação por encaminhamento ao emprego, mas os programas de qualificação ainda são incipientes em relação à demanda. Tal afirmação pode ser corroborada pela caracterização dessa massa de desempregados, onde se verificou, pelo referido estudo, que 39, 6\% eram oriundos do setor de serviços e tinham um tempo médio de procura por emprego equivalente a 39 semanas.

\section{Efeitos Psicossociais do Desemprego}

Dentre as conseqüências psicossociais do desemprego, destacam-se as 
afetações ao bem-estar psicológico do homem, intimamente relacionadas às ocorrências de deterioração do bem-estar físico, bem como de desagregação social. As principais afecções ao bem-estar psicológico, segundo Alvaro (1992), seriam: transtornos mentais leves (saúde mental geral), depressão, rebaixamento da auto-estima, sentimento de insatisfação com a vida, dificuldades cognitivas e dificuldades de relacionamento familiar. Tais aspectos constituem, segundo o autor, os principais focos dos estudos que tratam da associação entre desemprego e saúde mental. $\mathrm{O}$ autor compila informações de pesquisas empíricas que reforçam a existência de relações entre a situação de desemprego e a deterioração do bem-estar psicológico dos trabalhadores desempregados.

\section{Saúde Mental e Modelos Explicativos do Impacto do Desemprego}

É consenso, entre os estudiosos, que é difícil definir e operacionalizar o conceito de saúde mental. Warr (1987) apresenta explicações muito plausíveis para essa dificuldade. A primeira diz respeito à diversidade de interpretações e descrições que são dadas aos processos psicológicos, as quais são relacionadas a diferentes paradigmas. Tal divergência resulta na total impossibilidade de integração dos diferentes modelos explicativos. A segunda explicação é sobre o revestimento moral que acompanha os conceitos de saúde mental, conceitos esses geralmente fundados nos valores das classes dominantes de uma determinada sociedade. Saúde mental e doença mental não são, contudo, situações que permitam definir uma delas como ausência da outra; portanto, para examinar as relações entre o fenômeno do desemprego e a saúde mental, preservando o ponto de vista psicossocial, é mais adequado considerar as concepções de saúde mental em que o componente social e ambiental seja preponderante.

Tal concepção já é consolidada entre diversos autores, como Mirowsky e Ross (1989), que estabelecem clara distinção entre a idéia de doença mental e malestar, na qual a primeira se caracterizaria por um histórico evolutivo e uma estrutura nosológica comprovadamente instalada e integrada ao funcionamento geral do sujeito, enquanto a segunda seria a afetação do bem-estar psicológico ou uma variação negativa de um estado mais equilibrado ao qual o sujeito estaria habituado e com o qual conseguiria relacionar-se bem nas várias esferas de vida. Para os referidos autores, a doença mental se manifesta como estado subjetivo de mal-estar, marcado pela depressão e ansiedade e pelos seus derivados fisiológicos e emocionais.

Dentre os vários estudiosos que ressaltam o aspecto do bem-estar psicológico 
como indicador de saúde mental, destaca-se Warr que, diferentemente dos demais, concebe saúde mental considerando predominantemente os seus aspectos positivos. Warr (1987) entende, ainda, a saúde mental como multifatorial e identifica seus cinco componentes básicos: bem-estar afetivo, competência pessoal, aspiração, autonomia e funcionamento integrado. Segundo ele, desses cinco componentes é o bem-estar afetivo ou bem-estar psicológico que ocupa papel central para se averiguar o grau de saúde mental de uma pessoa.

Essa concepção de saúde mental que possibilita a integração dos resultados da investigação psicossocial sobre o desemprego a um contexto teórico é formulada no modelo vitamínico de Warr. Nele está proposto que o bem-estar psicológico do indivíduo (medida central da saúde mental) dependerá de quanto o seu ambiente psicossocial lhe proporciona oportunidades de experiências positivas, quanto estas são percebidas e como são aproveitadas. A explicação do processo de associação do desemprego e de suas conseqüências negativas no bem-estar psicológico das pessoas dá-se por meio de uma analogia entre a atuação dos fatores ambientais sobre o bem-estar psicológico do indivíduo e a influência das vitaminas na sua saúde física. Dado que a carência de vitaminas causa transtornos à saúde física e que a superdosagem destas não implica superfuncionamento do organismo, mas danos para ele, assim também o não atendimento às necessidades assinaladas por Warr (1987), como fatores de bom funcionamento psicossocial, acarretaria uma deterioração do bem-estar psicológico, à vista da situação de desemprego. Porém a elevação do atendimento de tais necessidades poderia ser inócua, a partir do seu limiar de saturação, ou até mesmo afetaria o bem-estar psicológico do trabalhador. Assim, o efeito causado pelas condições ambientais sobre o bem-estar psicológico é análogo ao das vitaminas sobre o organismo humano, conforme Figura 1.

\section{Figura 1: Representação Esquemática das Relações entre as} Características do Meio e a Saúde Mental

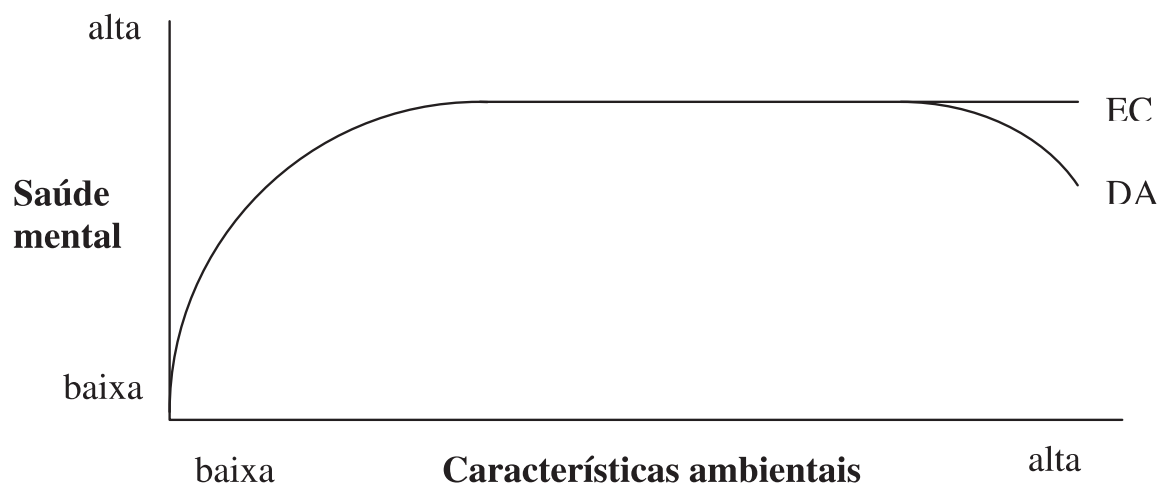

Observações: (EC = efeito constante; DA = diminuição adicional)

Fonte: Warr (1987, p. 10). 
Garrido (1996) comenta que há similaridades entre o modelo de privação de Jahoda e o modelo vitamínico de Warr, principalmente entre as categorias ambientais de Warr e as categorias de experiência de Jahoda. Ainda assim, as similaridades cessam no que diz respeito à exclusividade do emprego, enquanto catalisador das experiências estruturantes, proposta por Jahoda, contra a diversidade de fontes de influências ambientais, proposta por Warr.

\section{Metodologia}

Este desenho de pesquisa buscou atender às características dos estudos empíricos de linha investigativa psicossocial sobre desemprego, a partir da consideração do caráter multifacetado do conceito de saúde mental de Warr (1987), tomando seu componente central - o bem-estar psicológico - como indicador de saúde mental e variável dependente da pesquisa, o qual foi aferido entre trabalhadores empregados e desempregados pelo Questionário de Saúde Geral, de Goldberg (1972), em sua versão de 12 itens. Nesse caso, a variável independente é o estado ocupacional vivenciado pelo trabalhador na época da coleta de dados: empregado, se ocupado formalmente sob contrato de trabalho, regime similar ou autônomo, conforme registros formais exigidos para o exercício daquela atividade; desempregado, se desocupado e em busca de emprego ou ocupado irregularmente.

Optou-se pela análise comparativa entre as situações ocupacionais para efeito de comprovação, por procedimentos estatísticos, se tal condição se relaciona à deterioração do bem estar psicológico. Os resultados obtidos foram analisados principalmente sob o ponto de vista do conceito de saúde mental e do modelo explicativo de Warr (1987) para o impacto do desemprego sobre ela.

A amostra total constituiu-se de 642 sujeitos, divididos em duas subamostras, extraídas de universos distintos: trabalhadores empregados $(\mathrm{N}=184)$ e desempregados $(\mathrm{N}=458)$.

A coleta de dados foi realizada por meio de um protocolo em que consta o Questionário de Saúde Geral, QSG, com uma escala criada por Goldberg (1972). Trata-se de um instrumento amplamente utilizado entre diversos pesquisadores dos efeitos do desemprego, pela sua adequação à finalidade de aferir a saúde mental, por meio de seu componente bem-estar psicológico e por suas excelentes propriedades psicométricas que foram confirmadas em estudo piloto, em que 0 referido questionário foi traduzido, adaptado e validado para as populações locais (Borges; Argolo, 2000); um par de itens sobre centralidade do trabalho, utilizado, 
originalmente, pela equipe do Meaning of Work - MOW - e modificada por Soares (1992); um par de itens acerca da percepção de apoio social, percebido na situação de desemprego, elaborado pelo autor deste estudo; e ficha de dados ocupacionais e sociodemográficos.

\section{Resultados}

A hipótese central deste estudo está centrada no impacto da situação ocupacional no bem-estar psicológico dos trabalhadores e foi assim formulada: Os trabalhadores desempregados apresentarão deterioração do bem-estar psicológico maior que a dos empregados, quando controlados os efeitos das variáveis: idade, sexo, estado civil, nível de instrução e renda salarial.

Confirmou-se a hipótese central da pesquisa, pois se obteve uma média dos escores da deterioração do bem-estar psicológico significativamente maior para desempregados, em comparação aos empregados, cuja diferença é estatisticamente significativa, conforme Tabela 1. Estes valores encontram-se consoantes aqueles apontados em estudos similares, que variam, por exemplo, de 9,06 (Jackson et al., 1983) a 15,61 (Banks et al., 1980). Importa também ressaltar que a pontuação máxima, no presente estudo, foi de 31, quando a máxima possível é de 36 (12 itens com respostas pontuando de 0 a 3).

\section{Tabela 1: Médias dos Escores de Deterioração do Bem-estar Psicológico por Situação Ocupacional}

\begin{tabular}{lllll}
\hline Empregados & \multicolumn{4}{l}{ Desempregados } \\
\hline Média & Desvio-padrão & Média & Desvio-padrão & Teste $\mathrm{T}$ \\
\hline $\mathbf{9 , 7 9}$ & 5,83 & $\mathbf{1 2 , 3 4}$ & 6,88 & 4,431 para $\mathrm{p}<, 001$ \\
\hline
\end{tabular}

A fim de comprovar a consistência da diferença dessas médias em relação à situação ocupacional, realizou-se o teste "T" sobre a amostra total de sujeitos $(n=642)$. Para analisar a capacidade preditiva e a proporcionalidade na explicação da variância das variáveis independentes sobre os escores da deterioração do bem-estar psicológico, foram realizadas análises de regressão stepwise. A solução apresentada demonstra a destacada capacidade preditiva da variável situação ocupacional sobre a deterioração do bem-estar psicológico dos desempregados, uma vez que as demais variáveis independentes, introduzidas na equação, guardam coeficientes $B$ bem abaixo da condição de estar empregado ou desempregado; outras variáveis, como gênero, estado civil, idade, grau de instrução, cargo e setor produtivo, foram excluídas da equação. 
A fim de controlar o efeito das variáveis sociodemográficas e ocupacionais na comparação das médias de escores da deterioração do bem-estar psicológico, realizaram-se as análises de regressão sobre a amostra de empregados em separado ( $\mathrm{n}=184$ ), verificando-se que nenhuma variável apresentou capacidade preditiva sobre a deterioração de bem-estar psicológico, enquanto na amostra de desempregados $(\mathrm{n}=458)$ diversas variáveis apresentaram alguma capacidade preditiva, a saber: estado civil, número de filhos, freqüência à igreja, idade, participação no orçamento familiar e religião.

Os resultados obtidos na verificação da hipótese principal deste estudo coadunamse perfeitamente com resultados de estudos semelhantes, de diversas partes do mundo (tais como: Alvaro, 1992; Banks et al., 1980; Feather; Rowley, 1987; Niskanen; Koskela; Viinamäki, 1993). Na presente pesquisa, também foram obtidos resultados bastante positivos no sentido da comprovação de que a situação ocupacional, em relação às demais variáveis presentes no estudo, é a mais determinante da deterioração do bem-estar psicológico entre os trabalhadores da cidade de Natal, por ser a variável que apresentou maior poder de predição nas análises de regressão stepwise. Outro dado a ser considerado é a proporção da variância explicada $\left(r^{2}\right)$ por essa variável que, apesar de muito baixa, não sofre incrementos substanciais com a introdução das outras variáveis na equação. Além disso, o teste de controle das variáveis foi bastante satisfatório, porquanto, ao se realizarem análises de regressão com as amostras de empregados e desempregados em separado, introduzindo-se os dados sociodemográficos, observou-se que nenhum deles entrou na equação para a amostra de empregados, enquanto, na amostra de desempregados, sete das variáveis aplicadas se fizeram presentes.

\section{Variáveis Mediadoras Entre o Impacto do Desemprego e a Deterioração do Bem-Estar Psicológico}

Esta parte do estudo consiste em avaliar o poder mediador de algumas variáveis na relação entre o impacto do desemprego e a deterioração do bem-estar psicológico. As variáveis em estudo são gênero, idade, renda, participação no orçamento familiar, número de filhos, religião, freqüência à igreja, tempo de desemprego, centralidade do trabalho e apoio social percebido.

Gênero. Acerca da mediação desta variável no impacto do desemprego sobre a deterioração do bem-estar psicológico, foi formulada a hipótese (H2): Não haverá distinção significativa dos efeitos causados à saúde mental dos trabalhadores desempregados em razão do gênero. Tal hipótese foi 
confirmada, por não se encontrar diferença estatisticamente significativa entre as médias de deterioração do bem-estar psicológico por gênero.

Idade. Com relação à idade dos desempregados, esperava-se que o impacto do desemprego fosse maior em dada faixa etária, conforme a hipótese (H3): A reação ante a situação de desemprego será diferente em função da faixa etária, onde os trabalhadores de idades no intervalo entre 35 e 45 anos serão os mais afetados em seu bem-estar psicológico. A diferença entre as faixas etárias não se apresentou estatisticamente significativa pelo teste “T”. Tal resultado invalida, portanto, a hipótese formulada.

Porém cabe ressaltar que a idade se mostrou correlacionada significativamente à renda $(0,32)$, à participação no orçamento familiar $(0,41)$ e ao número de filhos $(0,60)$, com significância de $\mathrm{p}<0,01$.

Tempo de desemprego. Apesar de reiteradas constatações, em estudos anteriores, sobre a alta correlação entre idade e tempo de desemprego, no presente estudo, a correlação de Pearson entre essas variáveis foi de 0,131 para $\mathrm{p}<0,01$. Portanto, apesar de significativa, é correlação baixa, fato este que explica a ausência da variável tempo de desemprego nas análises de regressão e as diferenças não significativas entre as médias de deterioração do bem-estar psicológico em função do tempo que os sujeitos passam desempregados. Esse dado invalida a hipótese (H4) formulada neste estudo: Quanto mais prolongado for o período de desemprego maior será a deterioração do bem-estar psicológico dos trabalhadores, respeitado um ponto de saturação dos efeitos do desemprego, onde decrescerá o nível de deterioração do bemestar psicológico; portanto não há diferença estatisticamente significativa da deterioração do bem-estar psicológico entre os desempregados da amostra, aferida pelo tempo de desemprego.

Renda. A variável renda foi examinada enquanto mediadora do impacto do desemprego sobre a deterioração do bem-estar psicológico. Considerando-a no caráter contínuo (variação entre a última renda de emprego e a renda atual), não se observou significância estatística na diferença entre as médias de deterioração do bem-estar psicológico, invalidando a hipótese (H5), assim formulada: Quanto mais negativa for a variação entre a renda percebida no emprego e a renda no desemprego, maior será a deterioração do bem-estar psicológico do desempregado. Mas, ao considerarmos apenas a existência ou não da renda no desemprego, observou-se em tal variável dicotomizada significância estatística entre as médias de deterioração do bem-estar psicológico para os grupos com renda e sem renda, cuja comprovação dos dados pela ANOVA, e significativa capacidade preditiva, que foi sustentada pela Análise de Regressão, conforme a Tabela 2. 
Tabela 2: Médias de Deterioração de Bem-estar Psicológico por Existência de Renda no Desemprego

\begin{tabular}{lll|lcc|ll}
\hline Renda & Média & Desvio-padrão & \multicolumn{3}{|l|}{ ANOVA } & & \multicolumn{2}{|l}{ REGRESSION } \\
\hline Sem renda & 12,58 & 6,89 & F & df & Sig. & B & $\mathrm{r}^{2}$ \\
& & & 5,475 & 1 & p $<0,05$ & 2,652 & 0,01 \\
Com renda & 9,93 & 6,42 & & & & & \\
\hline
\end{tabular}

Participação no orçamento familiar. Foi hipotetizado (H6): Quanto maior a participação do trabalhador no orçamento familiar, na situação de emprego, maior seria o grau de deterioração do seu bem-estar psicológico, quando desempregado. Verificou-se uma associação significativa entre a participação no orçamento e as médias de deterioração de bem-estar psicológico, quer considerando-se a primeira em seu caráter contínuo (0 a 100\%) ou quando se criaram intervalos de distribuição. No entanto não há relação linear de proporcionalidade entre as variáveis, ou seja, verificou-se uma faixa de participação no orçamento (de 50 a 90\%) na qual a média de deterioração é mais alta; porém decresce levemente, quando chega a 100\% de participação. A prova estatística que sustenta esses dados é a ANOVA, conforme Tabela 3.

Tabela 3: Médias de Deterioração de Bem-estar Psicológico por Participação no Orçamento Familiar na Amostra de Desempregados

\begin{tabular}{|c|c|c|c|c|c|c|c|}
\hline & Média & $\begin{array}{l}\text { Desvio- } \\
\text { padrão }\end{array}$ & $\begin{array}{l}\text { ANC } \\
\text { F }\end{array}$ & $\mathrm{df}$ & Sig. & \multicolumn{2}{|l|}{ Teste "T" } \\
\hline $\begin{array}{l}\text { Entre } 40 \\
80 \%\end{array}$ & 13,63 & 7,10 & & & & $-3,572$ & \\
\hline $\begin{array}{l}\text { Participação } \\
\text { Até } 40 \%\end{array}$ & 10,82 & 6,12 & 7,21 & 1 & $\mathrm{p}=0,01$ & & $\begin{array}{l}-3,095 \\
p=0,002\end{array}$ \\
\hline De 80 a $100 \%$ & 13,33 & 7,38 & & & & & \\
\hline
\end{tabular}

Verifica-se, portanto, que a função econômica do sujeito no grupo familiar tem papel mediador na relação entre o desemprego e o bem-estar psicológico. Observa-se que os sujeitos com papel coadjuvante na economia familiar (até $30 \%$ ) exibem médias mais baixas de deterioração do bem-estar psicológico, enquanto, a partir de uma proporção tendente à igualdade (40\%) e até à totalidade (100\%), as médias são bem mais altas, sendo insignificante a 
diferença entre os grupos de desempregados com participação de 40 a $80 \%$ e com mais de $80 \%$. Cabe ressaltar ainda que a maioria (55\%) dos sujeitos, com participação no orçamento de até 30\%, está na faixa etária entre 14 e 24 anos, faixa esta onde estão àqueles que buscam o primeiro emprego e também os que exibem as menores médias de deterioração de bem-estar psicológico neste estudo.

Número de filhos. Esta variável foi introduzida com a finalidade de observar quanto o fato de ter filhos a sustentar pode mediar o impacto do desemprego sobre a deterioração do bem-estar psicológico. A hipótese (H7) sobre seu papel mediador foi assim formulada: Haverá uma correspondência direta entre o aumento do número de filhos e o aumento da deterioração do bem-estar psicológico na situação de desemprego.

Confirmou-se a referida hipótese por meio da diferença estatisticamente significativa entre as médias de deterioração de bem-estar psicológico, testada pela ANOVA, observando-se o seu crescimento de acordo com o aumento do número de filhos, conforme a Tabela 4.

\section{Tabela 4: Médias de Deterioração de Bem-estar Psicológico por Número de Filhos}

\begin{tabular}{|c|c|c|c|c|c|}
\hline & Média & Desvio-padrão & \begin{tabular}{|l} 
ANOVA \\
$\mathrm{F}$
\end{tabular} & $\mathrm{df}$ & sig. \\
\hline Sem filhos & 11,20 & 6,35 & & & \\
\hline Um filho & 12,90 & 6,80 & 15,077 & 1 & $\mathrm{p}<0,001$ \\
\hline filho & 13,96 & 7,45 & & & \\
\hline
\end{tabular}

Como no caso da participação no orçamento familiar, a presente variável reflete o peso da responsabilidade social como fator que medeia o impacto do desemprego sobre a afetividade dos trabalhadores. Nesse estudo optou-se pelos dependentes financeiros da categoria filhos, mesmo sabendo-se que existem outras categorias de dependentes, pois esta é, sem dúvida, a categoria que, por excelência, tipifica a responsabilidade social de provisão de recursos materiais para a sobrevivência e educação e que, portanto, interfere mais diretamente no estado emocional dos desempregados.

Centralidade do trabalho. Fundamentando-se em achados de estudos anteriores (Alvaro, 1992), formulou-se a seguinte hipótese (H8): Haverá direta correspondência entre o grau de centralidade do trabalho percebido pelo trabalhador desempregado e o nível de deterioração do seu bemestar psicológico. Os resultados da verificação dessa hipótese são contrários 
àqueles descritos na bibliografia consultada: não foram encontradas diferenças significativas nas médias de deterioração de bem-estar psicológico em razão do grau de centralidade do trabalho atribuído pelos desempregados da amostra. No entanto cabe assinalar alguns aspectos relevantes desse resultado: a) supõese que os itens eleitos para aferir o grau de centralidade do trabalho tenham sofrido distorções pela situação de coleta de dados, uma vez que esta ocorreu no momento de espera pela entrevista de emprego no SINE e, provavelmente, atribuir valores absolutos e relativos à importância do trabalho, nessas circunstâncias, resultou numa distribuição de freqüência, em que $60 \%$ dos respondentes atribuíram valor absoluto máximo ao trabalho, assim como também 51,9\% dos sujeitos atribuíram valores acima da média de pontos esperados para cada área da vida (vide anexos).

Apoio Social Percebido. O apoio social percebido na situação de desemprego foi aferido por dois itens. O primeiro consistiu no somatório de escores atribuídos a seis formas básicas de apoio social: apoio material da família, apoio emocional da família, apoio material dos amigos, apoio emocional dos amigos, apoio material de instituições e apoio emocional de instituições. O segundo afere a percepção geral do sujeito sobre o apoio social recebido na situação de desemprego. A hipótese (H9) acerca dessa variável, como mediadora do impacto do desemprego sobre a deterioração do bem-estar psicológico, foi assim formulada: $\mathbf{O}$ nível de apoio social percebido pelos desempregados será inversamente proporcional ao de deterioração do seu bem-estar psicológico.

Os resultados obtidos e testados pela ANOVA apresentam forte distinção de magnitude no $F$ value entre o apoio social específico e o sentimento geral de apoio social, sendo este último portador de índice mais elevado. Constatou-se ainda que as associações significativas entre os subitens isolados e o somatório dos escores de deterioração de bem-estar psicológico ocorreram para apoio emocional familiar $(-0,26)$, apoio material familiar $(-0,15)$ e apoio material de amigos $(-0,12)$. Na Tabela 5 seguem os resultados do apoio social na percepção geral e específica.

Embora não tenha sido formulada nenhuma hipótese acerca do papel mediador da religião e da freqüência do hábito religioso das pessoas no impacto do desemprego sobre a saúde mental, seguem os resultados da exploração das referidas variáveis. 
Tabela 5: Médias de Deterioração do Bem-estar Psicológico por Nível de Apoio Social

\begin{tabular}{|c|c|c|c|c|c|}
\hline \multicolumn{6}{|c|}{ Apoio Social - $\Sigma$ das seis formas de apoio } \\
\hline & Média & Desvio-padrão & $\begin{array}{l}\text { ANOVA } \\
\text { F }\end{array}$ & $\mathrm{df}$ & Sig. \\
\hline Nenhum & 14,13 & 7,50 & \multirow{4}{*}{18,897} & \multirow{4}{*}{1} & \multirow{4}{*}{$\mathrm{p}<0,001$} \\
\hline Fraco & 12,72 & 6,83 & & & \\
\hline Bastante & 11,63 & 6,89 & & & \\
\hline Total & 10,34 & 5,53 & & & \\
\hline \multicolumn{6}{|c|}{ Apoio Social - Percepção geral } \\
\hline Nenhum & 15,30 & 7,11 & \multirow{4}{*}{54,039} & & \multirow{4}{*}{$\mathrm{p}<0,001$} \\
\hline Fraco & 11,67 & 6,37 & & & \\
\hline Bastante & 9,00 & 5,08 & & & \\
\hline Total & 8,55 & 6,33 & & & \\
\hline \multicolumn{6}{|c|}{ Formas de apoio social específico } \\
\hline \multirow{3}{*}{\multicolumn{3}{|c|}{$\begin{array}{l}\text { Apoio emocional familiar } \\
\text { Apoio material familiar } \\
\text { Apoio material de amigos }\end{array}$}} & 33,296 & 1 & $\mathrm{p}<0,001$ \\
\hline & & & 10,117 & 1 & $\mathrm{p}<0,01$ \\
\hline & & & 6,587 & 1 & $\mathrm{p}<0,05$ \\
\hline
\end{tabular}

Religião. Utilizando-se a ANOVA, foi observada diferença significativa entre as médias de deterioração do bem-estar psicológico em função da religião dos desempregados. Tal diferença entre as médias reside, efetivamente, entre desempregados sem religião e evangélicos, e foi comprovada pelo teste "T", conforme se observa na Tabela 6.

Tabela 6: Médias de Deterioração do Bem-estar Psicológico por Religião

\begin{tabular}{lll|lcl}
\hline & & & ANOVA & & \\
Religião & Média & Desvio-padrão & $\mathrm{F}$ & df & Sig. \\
\hline Sem religião & 13,95 & 7,17 & & & \\
Católicos & 12,59 & 6,78 & 5,005 & 1 & 0,026 \\
Evangélicos & 11,01 & 7,33 & & & \\
Espíritas & 11,00 & 5,61 & & \\
Outras & 11,17 & 6,00 & \multicolumn{5}{l}{ Teste "T" } \\
\hline \hline
\end{tabular}

Observou-se, ainda, a rejeição da independência entre as variáveis Religião e Freqüência à igreja quando se aplicou o teste do Qui-quadrado em tabelas cruzadas das mesmas, conforme Tabela 7. 


\section{Tabela 7: Tabelas Cruzadas e Qui-quadrado entre Religião e Freqüência à Igreja, em Porcentagens}

\begin{tabular}{|c|c|c|c|c|c|}
\hline \multirow{2}{*}{ Religião } & \multicolumn{5}{|c|}{ Frequiência à igreja } \\
\hline & Semanal & $\begin{array}{l}\text { Quase } \\
\text { semanal }\end{array}$ & $\begin{array}{l}\text { Ás vezes e em } \\
\text { datas especiais }\end{array}$ & $\begin{array}{l}\text { Só em datas } \\
\text { especiais }\end{array}$ & Não freqüento \\
\hline Sem religião & $2,3 \%$ & $2,3 \%$ & $11,6 \%$ & $4,7 \%$ & $79,1 \%$ \\
\hline Católicos & $17,9 \%$ & & $16,6 \%$ & $12,0 \%$ & $9,0 \%$ \\
\hline Evangélicos & $64,1 \%$ & $14,1 \%$ & $10,3 \%$ & $3,8 \%$ & $7,7 \%$ \\
\hline Espíritas & $33,3 \%$ & $22,2 \%$ & $33,3 \%$ & & $11,1 \%$ \\
\hline Outras & $9,1 \%$ & $13,6 \%$ & $59,1 \%$ & $13,6 \%$ & $4,5 \%$ \\
\hline \multicolumn{6}{|l|}{ Qui-quadrado } \\
\hline $\begin{array}{l}\text { Valor } \\
237,379\end{array}$ & & $\begin{array}{l}\text { Graus } \\
16\end{array}$ & dade & $\begin{array}{l}\text { Significância } \\
\mathrm{p}<0,001\end{array}$ & \\
\hline
\end{tabular}

Freqüência à igreja. Esta variável apresentou significativa associação com as médias de escores da deterioração do bem-estar psicológico, quando explorada por análise de variância, sendo também significativa a diferença entre tais médias, conforme a Tabela 8.

\section{Tabela 8: Médias dos Escores de Deterioração do Bem-estar Psicológico por Freqüência à Igreja}

\begin{tabular}{|c|c|c|c|c|c|}
\hline \multirow[b]{2}{*}{ Frequiência à igreja } & \multirow[b]{2}{*}{ Média } & \multirow{2}{*}{$\begin{array}{l}\text { Desvio- } \\
\text { padrão }\end{array}$} & \multicolumn{3}{|l|}{ ANOVA } \\
\hline & & & $\mathrm{F}$ & $\mathrm{df}$ & Sig. \\
\hline $\begin{array}{l}\text { Semanalmente } \\
\text { Quase } \\
\text { semanalmente }\end{array}$ & 10,62 & 6,62 & & & \\
\hline $\begin{array}{l}\text { Eventualmente e em } \\
\text { datas especiais }\end{array}$ & 12,85 & 6,66 & 12,346 & 1 & $\mathrm{p}<0,001$ \\
\hline $\begin{array}{l}\text { Apenas em datas } \\
\text { especiais }\end{array}$ & 11,75 & 6,37 & & & \\
\hline \multirow[t]{2}{*}{ Não freqüenta } & 14,57 & 7,64 & & & \\
\hline & & & $\begin{array}{l}\text { Teste "T" } \\
\mathrm{t}\end{array}$ & $\begin{array}{l}\text { Graus de } \\
\text { liberdade }\end{array}$ & Significância \\
\hline $\begin{array}{l}\text { Semanalmente } \\
\text { Eventualmente e em } \\
\text { datas especiais }\end{array}$ & $\begin{array}{l}10,62 \\
12,85 \\
\end{array}$ & $\begin{array}{l}6,62 \\
6,66 \\
\end{array}$ & $-2,719$ & 271 & 0,007 \\
\hline $\begin{array}{l}\text { Semanalmente } \\
\text { Não frequienta }\end{array}$ & $\begin{array}{l}10,62 \\
14,57 \\
\end{array}$ & $\begin{array}{l}6,62 \\
7,64 \\
\end{array}$ & $-3,657$ & 177 & $\mathrm{p}<0,001$ \\
\hline $\begin{array}{l}\text { Apenas em datas } \\
\text { especiais }\end{array}$ & 11,75 & 6,37 & \multirow[t]{2}{*}{$-2,034$} & \multirow[t]{2}{*}{111} & \multirow[t]{2}{*}{0,044} \\
\hline Não freqüenta & 14,57 & 7,64 & & & \\
\hline
\end{tabular}


De modo geral, o presente estudo obteve resultados que apontam algumas concordâncias com estudos anteriores, mas também assinalam algumas distinções, que, provavelmente, decorrem das particularidades socioculturais da localidade onde o estudo ocorreu.

\section{Conclusões}

Os resultados obtidos confirmam a deterioração do bem-estar psicológico em razão do desemprego, hipótese principal deste estudo, e se coadunam perfeitamente com resultados de estudos semelhantes de diversas partes do mundo, tais como: Alvaro, 1992; Banks et al., 1980; Feather; Rowley, 1987; Niskanen; Koskela; Viinamäki, 1993.

Embora estudos transversais como este sofram a crítica da limitação em possibilitar a afirmação de que a situação ocupacional pode também ser efeito da deterioração do bem-estar psicológico e não apenas causa desta, os procedimentos metodológicos aqui tomados podem minimizar essa fragilidade, até mesmo no sentido da comprovação de que a situação ocupacional, em relação às demais variáveis presentes, é a mais determinante e preditora do sofrimento psicológico.

O sofrimento psicológico no desemprego pode ser entendido, sob o ponto de vista de Warr (1987), como a redução integrada da influência positiva das categorias ambientais ou oportunidades propostas pelo autor como fatores de construção e manutenção dos componentes da saúde mental.

As médias de deterioração do bem-estar psicológico entre desempregados, em outros países, mostram-se, em quase todos os estudos da bibliografia consultada, superiores às encontradas nesta pesquisa. Logo, é adequado inferir que há diferenças quanto ao impacto do desemprego sobre o bem-estar psicológico dos trabalhadores mediante características sociodemográficas e ocupacionais de cada localidade.

Quanto ao papel mediador da condição de gênero entre os desempregados, verificou-se que tanto homens quanto mulheres apresentaram deterioração significativa do bem-estar psicológico, se comparados aos respectivos sujeitos na amostra de empregados. Alinhado com a bibliografia consultada, o presente estudo revela que entre os trabalhadores da cidade de Natal o impacto do desemprego sobre a saúde mental não é significativamente distinto entre os sexos. Tal constatação, no entanto, conduz à reflexão sobre a atenção dispensada aos desempregados, em suas necessidades específicas, em razão do gênero. 
Os dados do IBGE (2000) revelam maior número de mulheres que de homens na Cidade de Natal, até mesmo em idade economicamente ativa; no entanto, segundo o DIEESE (2000), os números da taxa de participação no mercado de trabalho entre os sexos (homens 63,1\% e mulheres 41,8\%) não acompanham tal proporção. Assim, quando encontramos, no presente estudo, 59,8\% dos desempregados homens e 40,2\% mulheres, deparamo-nos com uma distorção da realidade, causada pela fraca inserção da mulher no mercado de trabalho. Logo, supõe-se que constatar entre os gêneros uma igualdade de sofrimento psicológico pelo desemprego é uma revelação qualitativa subdimensionada pelos erros de contagem deste último, ou seja, a sistemática de contagem oficial de desemprego suprime grande parte das mulheres que estariam ocupadas em tarefas domésticas ou similares, portanto sem condições objetivas de buscar emprego continuamente. Logo, parece haver aqui exclusão de duplo sentido: as mulheres têm menor participação no mercado de trabalho e desaparecem nas pesquisas, como ocupadas em projetos ocupacionais alheios à sua vontade. Estudos empíricos específicos sobre a condição do desemprego e seus efeitos em razão do gênero, na comunidade local, podem auxiliar na melhor compreensão do problema e na elaboração de estratégias para seu enfrentamento.

Constatou-se também que é inócua a influência da idade sobre a deterioração do bem-estar psicológico entre os desempregados da amostra, pelo fato de não ser estatisticamente significativa a diferença entre as médias de deterioração. Este parece ser mais um dado de particularidade da população estudada, visto que na maioria dos estudos consultados, tal variável tem poder significativo de interferência nas médias de deterioração do bem-estar psicológico. Assim, é possível afirmar que os motivos da deterioração do bem-estar psicológico estão relacionados, de modo equânime, à situação ocupacional em todas as faixas etárias da população estudada.

Tal achado aponta para reflexões acerca das políticas públicas empreendidas e para a questão da requalificação como instrumento para incrementar a empregabilidade dos trabalhadores. O discurso dos organismos governamentais e da mídia em geral acerca da empregabilidade é, sobremaneira, voltado para a população mais jovem, identificada no presente estudo, como o segmento de 14 a 25 anos; mas verificou-se, nesta pesquisa, que o sofrimento psicológico causado pelo desemprego não varia de acordo com a idade. À luz dos pressupostos de Warr (1987), sobre os componentes positivos da saúde mental, advindos da relação com o ambiente psicossocial, pode-se afirmar: na população estudada, as funções latentes do emprego estariam sendo prejudicadas pela ausência de um posto de trabalho, a despeito da variação do tipo e intensidade de suas necessidades relativas à faixa etária.

Os achados desta pesquisa em relação às variáveis Renda, Participação no orçamento e Número de filhos, enquanto mediadores do impacto do desemprego, 
estão alinhados com a explicação de Warr (1987), a respeito da influência da disponibilidade de recursos financeiros no ambiente para fazer frente às necessidades do indivíduo e, assim, favorecer o equilíbrio emocional. É interessante frisar que para a variável Renda não se encontrou associação significativa com o nível de deterioração de bem-estar psicológico, quando esta se encontrava em seu caráter contínuo ( $\mathrm{n}^{\circ}$ de salários-mínimos), ou seja, a variação de renda não se fazia acompanhar pela variação do bem-estar psicológico; porém, quando posta em caráter dicotômico (com ou sem renda no desemprego), a renda passou a influenciar significativamente as médias de deterioração, alcançando destacada capacidade preditiva da saúde mental, se comparada com as demais variáveis. De certo modo, esse resultado reflete a proposição de que a disponibilidade financeira do ambiente possui um ponto de saturação, ou seja, a partir de um dado ponto, o seu crescimento deixa de produzir aumento de bem-estar psicológico, enquanto a sua diminuição até à ausência causa deterioração do bem-estar psicológico.

Assinala-se, ainda, que as variáveis que compõem este aspecto socioeconômico se apresentaram correlacionadas, sendo que entre a participação no orçamento e o número de filhos, o índice de correlação foi ainda mais acentuado. Isto reforça ainda mais a idéia de que as responsabilidades por encargos financeiros são confrontadas com a disponibilidade de recursos e, desse confronto, surge a influência sobre o bem-estar psicológico.

A ausência de associação significativa entre centralidade do trabalho e deterioração do bem-estar psicológico, entre os desempregados da amostra, merece uma observação, porque os itens que aferiram tal variável em seu aspecto relativo (comparação com outras áreas da vida) e absoluto (importância do trabalho) podem ter sofrido distorção conotativa, por terem sido respondidos em local e situação, em que os respondentes buscavam oportunidade de emprego. Apesar de todos os cuidados tomados para desvincular o trabalho de coleta de dados da pesquisa daquela finalidade, que motivava a presença dos trabalhadores naquele local, tomou-se a alta freqüência das respostas maximizadas e a sua fraca variabilidade como traço de duas possibilidades: a) indício da cultura de glorificação do trabalho e b) respostas contaminadas pela confusão acerca do propósito dos questionários aplicados momentos antes de uma entrevista para emprego.

Embora não tenha havido formulação de hipóteses para as variáveis relativas ao comportamento religioso, enquanto mediador do impacto do desemprego sobre a saúde mental e, mediante o caráter multivariado do estudo, assim como da importância de tal comportamento, principalmente na sociedade nordestina do Brasil, seguem-se algumas considerações sobre as variáveis.

Encontraram-se diferenças estatisticamente significativas entre as médias de deterioração do bem-estar psicológico em função das religiões professadas pelos 
respondentes, embora na análise de regressão tal variável tenha apresentado fraca capacidade preditiva do bem-estar psicológico. Mais importante que a fé professada pelos participantes da pesquisa, revelou-se a informação da freqüência às suas igrejas ou similares. Tal variável apresentou maior capacidade preditiva sobre a deterioração do bem-estar psicológico que a anterior, tanto quando disposta em sua forma original, isto é nominal com gradações de freqüência, como quando dicotomizada (freqüência regular e irregular). A diferença entre as médias, segundo a regularidade da freqüência à igreja, é bem marcante nos pontos extremos de freqüência, o que reforça ainda mais o poder de influência da prática religiosa na reação emocional ao desemprego, sendo mais bem esclarecido na perspectiva de um apoio social ao desempregado.

Explorando o apoio social percebido, com suas fontes definidas (item formado por nove respostas - subitens) e na forma original, ou de gradação nominal, percebeu-se ainda uma boa capacidade preditiva e proporcionalidade da explicação da variância da deterioração do bem-estar psicológico decrescida. Considerando a contribuição dos seus subitens, os resultados de apoio social, percebido na sua apresentação específica, dizem respeito, prioritariamente, aos elementos de apoio emocional familiar, apoio material familiar e apoio material de amigos. Tais resultados indicaram que o sentimento de apoio social influencia, sobremaneira, a reação emocional dos desempregados e que as fontes principais de apoio social, em termos comparativos, seriam as relações familiares e fraternas.

Por outro lado, comparando-se os somatórios da percepção de apoio social específico com a nominação da percepção geral, foi constatada a forte incidência de altas pontuações para o suporte social específico, seguida de uma resposta de fraco ou nenhum apoio social percebido (geral). Tal análise, associada aos resultados das análises de regressão dos subitens que compõem o suporte social específico, indicou que há a eleição das fontes principais de apoio social, como também a expectativa sobre tal apoio.

Em virtude das constatações referidas, o presente estudo poderia ser aproveitado em seu aspecto descritivo, para que houvesse continuidade na investigação desse fenômeno em nossa localidade, e como referencial de análise por parte das instituições, governamentais ou não, implicadas no enfrentamento do desemprego e de seus efeitos psicossociais, principalmente no que diz respeito ao bem-estar psicológico dos trabalhadores.

Artigo recebido em 01.11.2003. Aprovado em 09.05.2004. 
REFERÊNCIAS

ALVARO, J. L.

Desempleo y bienestar psicológico.

Madrid: Siglo XXI, 1992.

BANKS, M. H. et al.

The use of the General Health Questionnaire as an indicator of mental health in occupational studies. Journal of Occupational Psychology, Leicester, n.53, p.187-294, may 1980.

BORGES, L. O.

Significado do trabalho e socialização organizacional: um estudo empírico entre trabalhadores da construção habitacional e de redes de supermercados. 1998. 389f. Tese (Doutorado em Psicologia Social do Trabalho) - UNB, Brasília.

BORGES, L. O.;

ARGOLO, J. C. T.

Adaptação e validação de uma escala de bem-estar psicológico para estudos ocupacionais. Avaliação Psicológia. Revista do Instituto Brasileiro de Avaliação e Pesquisa Psicológica, Porto Alegre, v.1, n. 1, julho de 2002.

BRIEF, A. P.;

NORD, W. R.

Meanings of occupational work. Lexington: Lexington Books, 1990.

DIEESE.

O mercado de trabalho na grande Natal [mensagem pessoal]. Mensagem recebida por <jocarte@ufrnet.br>em 20 dez. 2000.
FREYSSINET, J.

Le chômage. Paris : La Découverte, 1994.

GARRIDO,A.

Psicología social del desempleo. In: ALVARO, J. L.; TORREGROSA, J. R.; GARRIDO LUQUE, A. Psicología social aplicada. Madrid: McGraw-Hill: Interamericana de España, 1996. p.122152.

\section{GOLDBERG D.P.}

The detection of psychiatric illness by questionnaire: a technique for the identification and assessment of nonpsychotic psychiatric illness. London: Oxford University Press, june 1972

IBGE.

Disponível em: <http:// www.ibge.gov.br/cidades>. Acesso: em: 23 set. 2000

JACKSON, P. R. et al.

Unemployment and psychological distress in young people: the moderating role of employment commitment. Journal of applied psychology, Washington, v. 68, n. 1, p.525-535, feb. 1983.

\section{JAHODA, M.}

Empleo y desempleo: un análisis sociopsicológico. Madrid: Morata, 1987. 
JAHODA, M.;

LAZARSFELD, P. F.;

ZEISEL, $\mathrm{H}$.

Marienthal: the sociography of an unemployed community. Nova York: Aldine-Atherton, 1972.

KON, A.

Reestruturação produtiva e terceirização. São Paulo: Núcleo de Pesquisas e Publicações - EAESP, Fundação Getúlio Vargas, n.29, p.342, 1997. Relatório de Pesquisa

MIROWSKY, J.;

ROSS, C.E.

Social causes of psychological distress. New York: Aldine de Gruyter, 1989.

ROWLEY, K. M.;

FEATHER, N. T.

The impact of unemployment in relation to age and length of unemployment. Journal of occupational psychology, Leicester, n.60, p.323-332, apr. 1987.
SOARES, C. R. V.

Significado do trabalho: um estudo comparativo de categorias ocupacionais. 1992. 128f. Dissertação (Mestrado em Psicologia Social do Trabalho) - Universidade de Brasília, Brasília.

VIINAMÄKI, H.;

KOSKELA, K.;

NISKANEN, L.

The impact of unemployment on psychosomatic symptoms and mental well-being. International journal of social psychiatric, Londres, v. 39, n. 4, p. 266-273, dec. 1993.

WARR, P.

Work, unemployment and mental health. Oxford: Oxford University Press, 1987. 